\title{
Quasi-Free Goods and Social Norms: The Effects of Quantity Restrictions and Scrutiny
}

\author{
Shlomi Boshi* \\ Moshik Lavie ${ }^{* *}$ \\ Avi Weiss ${ }^{* * *}$
}

\begin{abstract}
In this paper we consider the effect of quantity restrictions and scrutiny on the consumption of quasi-free goods. A good is quasi-free if it is zero priced, but it is consumed in the context of a social setting (e.g., as an employee, client, friend, etc.). Examples include cookies at a picnic, candies in a doctor's office, and perks offered to workers such as free soft drinks. Casual observation, including initial experience with unlimited vacation policies by some major companies (Evernote, IBM, Bestbuy), suggests that placing limitations on consumption can lead to an increase in the level of consumption of such goods, while removing existing limitations (as in the case of vacations) may result in a decrease in consumption. We attribute this to the consumer's perceptions about the social norm and how this perception is affected by the presence of a quantity restriction. In this paper we develop a simple model of quasi-free goods consumption showing the effect of a quantity restriction and of observability of the consumer's actions, and then test the model in a field experiment. The results clearly show that allowing unlimited consumption leads to less consumption, however, such behavior all but disappears when the subjects' choices are unobserved, including by the experimenter. This suggests that consumers are more concerned with how they are perceived by others than with self-image concerns.
\end{abstract}

November 2014

* Department of Economics, Bar-Ilan University, Ramat-Gan, Israel Shlomiboshi@gmail.com

** School of Accounting, Shaarei Mishpat, Hod-Hasharon, Israel moshiklavie@ gmail.com

*** Department of Economics, Bar-Ilan University, Ramat-Gan, Israel and IZA, Bonn, Germany avi.weiss@ biu.ac.il

We would like to thank participants at the 2014 Israel Economic Association meetings, the 2014 ESA International Meetings and the $13^{\text {th }}$ TIBUR symposium on Psychology and Economics for helpful comments. We thank Avihood Baron and Avichai Hachmon for excellent research assistance. We gratefully acknowledge financial support from the Adar Foundation of the Economics Department at Bar-Ilan University. 


\section{Introduction}

The law of demand is one of the most basic tenets of economics. Yet, as has been demonstrated in numerous different contexts, when price falls to zero something fundamental changes, and this tenet turns tenuous. More specifically, making something free can often lead to a decrease in consumption rather than to the usual increase generally observed when prices fall. ${ }^{1}$ Fiske's Relational Theory (1992) explains this behavioral oddity by positing that when money is involved in a transaction the norms and rules that people invoke relate directly to market norms of exchange and to cost-benefit analyses, but in the absence of monetary considerations transactions are treated as social, and people apply societal norms to the exchange. In other words, consumer demand for free goods tends to be based largely on non-market considerations, centering on self-image, reputation, and norm concerns that might reduce consumption.

This, of course, is not always the case. To take an extreme example, air is free, but there are no personal or social implications for consuming as much air as one desires. ${ }^{2}$ The same is true in some instances for water; if one is drinking from a water fountain in a public building, one tends not to be concerned with any implications of drinking a lot. However, these would seem to be the exceptions. In most instances zero-priced goods are consumed in a social context, and social considerations apply. We define free goods consumed in a social context as "quasi-free goods," and consider consumption decisions of such goods under different conditions.

Quasi-free goods are relatively common. Banks fill bowls with free candies. A friend brings cookies to a picnic or to work. ${ }^{3}$ Kiosks offering free trials of goods are common in malls and supermarkets. In the workplace, companies offer perks such as free coffee and soft drinks, but these are available only for workers - individuals who are part of a distinctive social group in which normative considerations apply. In some instances the market value of the quasi-free goods is substantial. For example, an increasing portion of U.S corporations (some sizable, such as Netflix, Virgin, IBM and BestBuy) offer their workers an unlimited number of paid vacation and/or sick-leave days. According to

\footnotetext{
${ }^{1}$ This effect is not universal. For instance, Shampan'er and Ariely (2006) show that when offered a choice of goods at different prices, consumers tend to prefer a free good over a good with a minimal but positive price, even when the latter yields greater consumer surplus. The main explanation for this effect, according to Shampan'er and Ariely, is a psychological mechanism through which agents prefer alternatives with no downside (i.e., cost), while non-free alternatives, even when the cost is minimal, do not invoke such positive affective responses (Slovic et al., 2002). Nicolau and Sellers (2012) showed that the same effect exists for bundles that include one free product (buy $\mathrm{x}$ and get $\mathrm{y}$ free).

${ }^{2}$ Clean air, of course, is a different issue.

${ }^{3}$ Ariely, et al. (2008).
} 
SHRM (2014), in 2013, $1 \%$ of US companies offered unlimited time-off vacation and $3 \%$ offered unlimited paid sick time (an increase from $0 \%$ in 2011 , and $2 \%$ in 2012). ${ }^{4,5}$

In all the above examples, although the market cost of consumption is zero, the "social cost" might be positive. As Ariely, Gneezy and Haruvy (2008) explain, a zero price gives rise to social courtesies a consumer must consider in the process of deciding how much to consume. Based on this line of thought, a consumer's utility function should include social-regarding arguments in her utility function in addition to the more usual self-concerned arguments. When a good is a quasi-free good, the weight placed on the social considerations will be large. As a result, the consumer's choice will depend critically on what is considered to be a "socially acceptable" amount of consumption (the "norm") and on whether and how the consumption choice is regulated.

More specifically, when choosing how much of a quasi-free good to consume, the consumer must first form some assessment of the norm (i.e., the socially acceptable consumption level), and then evaluate the social cost of consumption. This cost increases with the size of the deviation from the norm and with the magnitude of any negative externality on others, e.g., due to scarcity of the good (if I eat another cookie fewer will remain for others in my social circle). However, as expounded upon below, both the assessment of the norm and the determination of the cost function may depend on the specific setting, including whether restrictions are placed on consumption, and if so, on whether they are enforced.

In some instances, the supplier of the quasi-free good places a quantity restriction on consumption. Stores offering a free giveaway in order to attract customers may limit consumption to "one per customer." Companies with free lunch cafeterias for their workers may issue coupons predetermining the value of the meal subsidized. Others allow workers to consume soft drinks for free, but limit them to

\footnotetext{
${ }^{4}$ Society for Human Resource Management. 2014. "2014 Employee Benefits: An Overview of Employee Benefits Offerings in the U.S.” (http://www.shrm.org/Research/SurveyFindings/Documents/14-0301\%20Beneftis_Report_TEXT_FNL.pdf).

${ }^{5}$ A 2010 survey found that an increasing number of businesses are shifting towards "unlimited vacation policies," which allows employees the freedom to take as many vacation days as they desire, with no limitations or monitoring, as long as they get the job done (WorldatWork "Paid Time Off Programs and Practices." (http://www.worldatwork.org/waw/adimLink?id=38913)). This policy is especially popular with silicon-valley small and medium companies such as Netflix, Zynga, Evernote and Hotel Tonight (MacMillan, Douglas “To Recruit Techies, Companies Offer Unlimited Vacation.” Bloomberg Businessweek, July 2012 (http://www.businessweek.com/articles/2012-07-19/to-recruit-techies-companies-offer-unlimited-vacation)), but large corporations such as IBM and Best Buy successfully implemented it as well (Belson, Ken "At I.B.M, a Vacation Anytime, or Maybe None." The New York Times, August 2007 (http://www.nytimes.com/2007/08/31/nyregion/31vacation.html?_r=0)). The concept is that the employee, as a responsible mature individual, is measured according to work output, and not according to time spent by his office desk. This policy is part of a holistic HR management strategy called "Results-Only Work Environment" (ROWE), see Ressler and Thompson (2008); Blakely, Lindsay "What is a Results-Only Work Environment?" MoneyWatch, September 2008 (http://www.cbsnews.com/8301-505125_162-51237128/what-is-a-results-only-work-environment).
} 
some number of cans per week. And, of course, the number of vacation and sick days allowed per year tends to be restricted in the vast majority firms. Surprisingly, casual observation suggests that average consumption levels are often higher when consumption of a quasi-free good is restricted than when it is unrestricted. For instance, it has been observed that workers in Israeli companies that offer unlimited consumption of soft drinks consume less on average than do workers in companies that place a quantity restriction on such consumption. Such seems to be the case also for unlimited vacation policies. ${ }^{6,7}$ To see why this seemingly perverse reaction is not actually surprising at all, we appeal to the thesis that when consuming quasi-free goods the focus of the consumer shifts from a market-based decision to one based on norms. ${ }^{89}$ When no quantity restriction exists the consumer's assessment of the socially acceptable quantity is made in a vacuum, but when a restriction exists it serves as a beacon, and this may affect the consumer's belief about the norm. We posit that if the restriction is greater than the perceived norm in the absence of a restriction then the perceived norm will increase, which will, consequently, increase the quantity consumed. ${ }^{10}$

A second determinant of consumption choice of quasi-free goods is observability. Considering the question of how a social norm is enforced, Kandori (1992) distinguishes between personal enforcement and community enforcement, where a necessary condition for community enforcement is

\footnotetext{
${ }^{6}$ When asked about the unlimited vacation policy impact on his company, Phil Libbin, CEO of Evernote responded: "The first thing we noticed when we did it was that some people started taking less vacation." (MacMillan, supra, fn. 4). In fact, the impact of this policy change on employee's vacations seems to have been substantial, causing Evernote to make a unique offer to their employees; any employee taking a week-long vacation (at least) is given $\$ 1,000$ "spending money" over and above their regular salaries. (http://www.nytimes.com/2012/04/08/business/phil-libin-of-evernote-on-its-unusual-corporateculture.html?pagewanted=all).

${ }^{7}$ A little introspection may be useful. Researchers in Universities are, by design, allowed an essentially unlimited number of vacation days. We would ask the reader to consider how many vacation days he/she takes on average per year and compare it with the number offered in employment contracts in other types of workplaces.

${ }^{8}$ The effect of norms, social customs and other social mechanism, on agents' actions is not new to economists. .

${ }^{9}$ Deutsch and Gerard (1955) define normative social influences as those that cause an agent to adjust his behavior to society's expectations, which stems from the need for social acceptance and harmony.

${ }^{10}$ In other situations, quantity limitations can play another role; they can be simple and effective instruments, often used by vendors and advertisers, to manipulate customers and signal a product's scarcity. This is a known marketing tactic, aiming to make products seem unattainable, thus more desirable, which eventually leads to increased sales (Lynn, 1991). The customer will often interpret the quantity limitation as a signal for a top-quality or high-value product (Lynn, 1992), or as a signal for an attractive deal (Inman, Peter and Raghubir, 1997), which results in increased consumption. Previous empirical studies found that while such limitations lead to more frequent or greater volume purchases (Inman, Peter and Raghubir, 1997, and Verhallen and Robben, 1994), choices are affected by the extent of the limitation. Wansink, Kent and Hoch (1998) demonstrated that customer motivation for increased consumption is dependent on limitation size - low limitation ("up to 4 products") is a strong indication for customers that the deal is worthwhile, while high limitation ("up to 12 products") is a weaker signal, but it performs as an anchor that can significantly divert customer decisions, as it suggests to customers what may be viewed as reasonable consumption. See Kahneman and Tversky (1974) and Van Exel, et al. (2006) for a discussion of anchor effects.
} 
visibility (Soetevent, 2005 and Funk, 2005). ${ }^{11}$ Regarding personal enforcement, decades of experimental and empirical studies have demonstrated that in many situations other-considering effects enter as an argument in a consumer's utility function (e.g., Fehr and Schmidt, 1999). This is true even when actions are completely unobserved by others. Thus, when a consumer's choice affects other parties adversely, say due to scarcity, the consumer is likely to give some modicum of consideration to this in her decision, and limit consumption even when unobserved. In addition, self-reflection could also lead people to be concerned with following norms, even when actions are taken in complete privacy. However, several researchers have shown that pro-social behavior is less likely in anonymous scenarios, and Kandori (1992) considers the threat of community sanctions to be the more important enforcement tool. ${ }^{12}$ Thus, we expect consumer choice to be substantially different when actions are observed than when not. In general, however, since the social effects include both self-reflecting issues (feeling good about oneself) and reputation considerations, it is unclear a priori to what extent observability will affect behavior; if the former is the more dominant, scrutiny will have little effect on choice, but if the converse is the case, consumer behavior may differ substantially between the two circumstances.

In this paper, we develop a simple model of quasi-free goods consumption and then present the results of a field experiment designed to test the model. In our model, and in the ensuing field experiment, we differentiate between a situation in which there is a restriction on consumption and one in which there is no such restriction, and between a situation in which the consumer's choice is observed by some relevant party (e.g., an employer) and one in which behavior is unobserved (both with and without a restriction). The experimental results clearly show that allowing unlimited consumption leads to less consumption, however, such behavior all but disappears when the subjects' choices are unobserved. This suggests that conformity to social norms is motivated more by how one is perceived by others (the reputation effect) than by concern for one's own self-image. ${ }^{13}$

The paper is structured as follows. In Section 2 we develop a model of quasi-free goods, and show how consumption is expected to change as a function of a quantity restriction and how it is affected by observation of choice by relevant parties. Section 3 presents the experimental setup and presents and analyzes the results. We conclude in Section 4.

\footnotetext{
${ }^{11}$ Levitt and List (2007) used the term scrutiny instead of visibility.

${ }^{12}$ Hoffman, et al. (1994), Burnham (2003), and Nogami and Takai (2008).

${ }^{13}$ Note that our research differs from Gneezy and Rustichini (2000a, 2000b) in that, while they consider the effect of changing a price from zero to a positive price, differentiating between social transactions and market transactions, we consider only zero prices.
} 


\section{A Model of Quasi-Free Goods}

Our model is designed along the lines of that in Levitt and List (2007). We assume that consumer utility from consuming a quasi-free good contains both private and social components. Specifically, the consumer's utility depends on the quantity of the good consumed $(q)$, on how her consumption compares with what she perceives to be the "social norm" $(n)$, and on externalities her consumption inflicts on others. For expositional purposes, we assume a simple additive utility function:

$U=W(q)-D \theta_{i} C(q-n(R))-E(q \mid Z), \quad i=o, u$,

where $W, C$, and $E$ are functions, $D$ and $\theta_{i}$ are discrete (dummy) variables defined below, $R$ is a quantity restriction placed on consumption (if one exists), and $Z$ denotes variables through which the consumer's consumption imposes a negative externality on others.

The first term in (1) is the usual wealth $(W)$ component, with $W^{\prime}>0$ and $W^{\prime \prime}<0$. The second term, $C(q-n(R))$, represents a social/moral cost incurred if the consumer consumes more than what she perceives to be the social norm. This term is multiplied by two variables. The first is a dummy, with $D=1$ if $q>n$ and $D=0$ otherwise. In other words, a consumer suffers a utility loss if and only if she consumes more than what she believes is the social norm, but does not gain utility by consuming less than the social norm. $\theta_{i}$ also takes on one of only two values, depending on whether the consumer's choice is observed $(o)$ or unobserved $(u)$. More specifically, $\theta_{o}=1$ is a normalized value relevant when the consumer's choice is observed, and $0 \leq \theta_{u} \leq 1$ is the relevant value when the choice is unobserved, with $1-\theta_{u}$ reflecting the portion of the utility loss attributable to how she is affected by how she is perceived by others. Thus, if the consumer only cares about surpassing the social norm because of how others view her, then $\theta_{u}=0$. In the opposite extreme case in which the consumers choice depends solely on her own self-esteem and is unaffected by reputation effects, $\theta_{u}=\theta_{o}=1$. The utility cost from surpassing the social norm increases convexly as the gap increases: $C^{\prime}>0$ and $C^{\prime \prime} \geq 0$. In addition, we assume that this cost is significant as soon as the norm is passed; specifically, we assume that $\lim _{q-n \rightarrow 0} C^{\prime}=A \gg 0$. To this end, we will respecify this function as

$C(q-n(R))=A \cdot(q-n(R))+N(q-n(R))$, 
with $\lim _{q \rightarrow n+} N=0$, and $N^{\prime}>0$. Finally, the value of the perceived norm depends on whether a quantity restriction on consumption exists, and its level. We will denote $n_{\emptyset}$ as the perceived norm in the absence of a quantity restriction, and $n_{R}$ as the perceived norm when the restriction is $R$.

The final term in (1) represents utility loss from imposing a negative externality on other players, be it the firm for which she works or other consumers whose choices might be affected by her own. Thus, a worker may realize that taking too many work days will harm her employer, and therefore limit the number even when her choice is unobserved, so $E^{\prime} \geq 0$. For our experimental setting this function is specified in a manner that reflects the idea of a shortage:

$E\left(q_{i} \mid Z\right)=E\left(\frac{q}{Q}\right)$

where $Q$ denotes the total quantity available for all consumers. We will use this specification from this point, without loss of generality.

Replacing (2) and (3) in (1), unconstrained utility is maximized when:

$W^{\prime}=D \theta_{i}\left(A+N^{\prime}\right)+\frac{1}{Q} E^{\prime}$

Note that even if the consumer's choice is unobserved and the consumer has no self-image reason to limit consumption $\left(\theta_{u}=0\right)$, consumption may still be limited if she is concerned about the externality effect on others. Similarly, even if this altruistic concern is not an issue, i.e., if we eliminate the final term in Equation (1), consumption may still be affected by perceptions about the social norm, possibly even when unobserved (if $\theta_{u}>0$ ).

Consider first the situation in the absence of a quantity restriction. One pair of equilibria is presented in Figure 1, with $q_{\emptyset, o}^{*}$ denoting the optimal consumption level when the consumer's choice is observed and $q_{\emptyset, u}^{*}$ when it is unobserved (we assume in the Figure that $0<\theta_{u}<1$ ). Note that because scrutiny leads to an increase in $\theta_{i}$, the optimal quantity is greater when unobserved. Simple permutations to the graph show other possible equilibria. Thus, lowering the $W^{\prime}$ curve so that it intersects the top part of the vertical line at $n_{\emptyset}$ yields a situation in which the consumer consumes exactly $n_{\emptyset}$ when observed, but when unobserved she consumes more. If we 
lower the $W^{\prime}$ curve more so that it cuts the lower part of this line, the consumer consumes $n_{\emptyset}$ always.

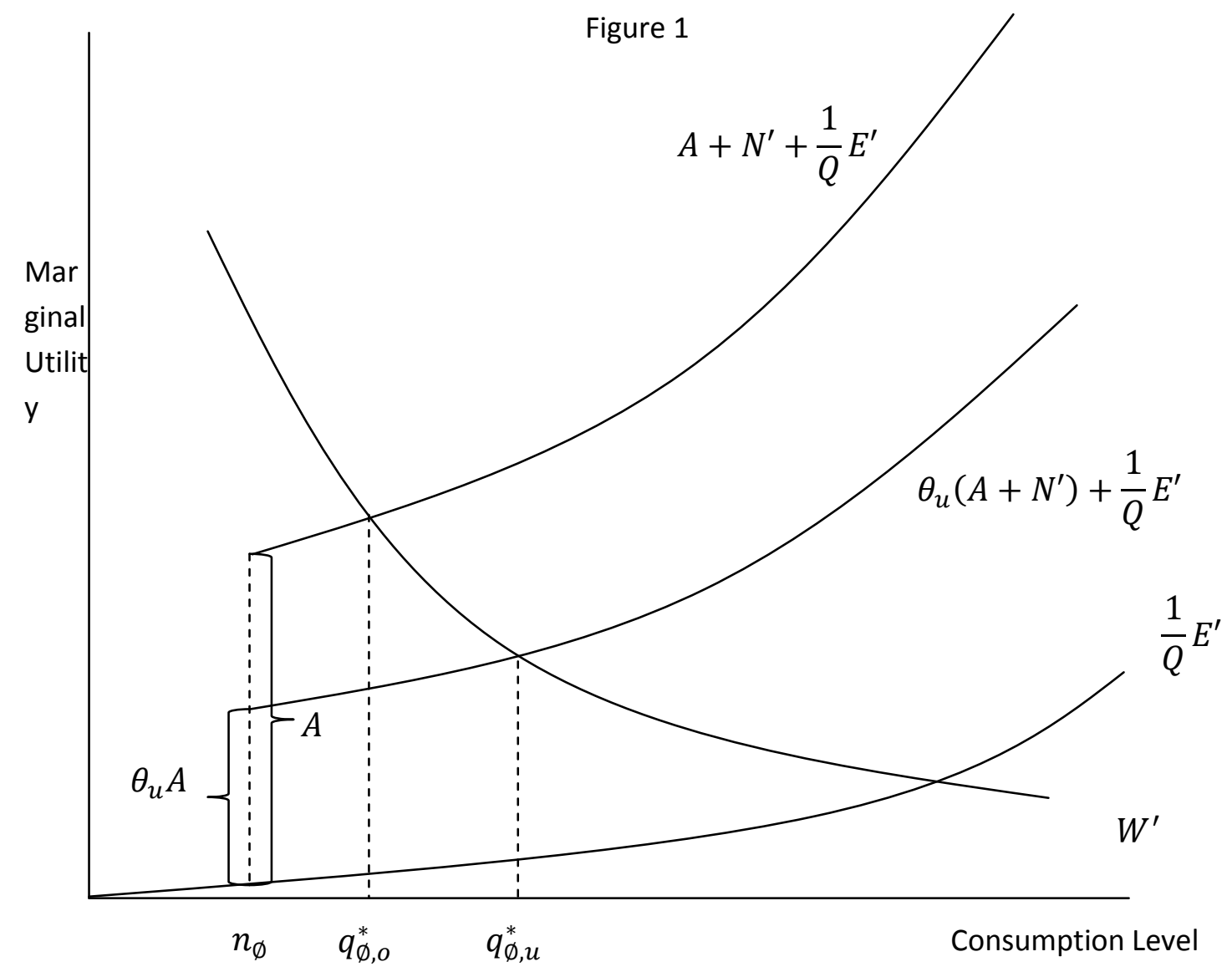

Consider now the effect of setting a consumption limit of $R>n_{\emptyset}$. Our main hypothesis is that specifying such a quantity restriction serves to increase the perceived norm either to the level of the limit or to some level below this limit, but above $n_{\emptyset}$, i.e., $n_{\emptyset}<n_{R} \leq R$. To this end, let us define the desired quantity after the change as

$q_{R, i}^{*} \equiv \operatorname{argmax}\left(W(q)-D \theta_{i}[A \cdot(q-n(R))+N(q-n(R))]-E\left(\frac{q}{Q}\right)\right), i=o, u$.

Note that the desired level of consumption increases when a restriction is placed on consumption because of the change in the perceived norm. Simple comparative statics show that:

$\frac{\partial q_{R, i}^{*}}{\partial R}=\frac{-U_{q n}}{U_{q q}} \frac{\partial n}{\partial R}=\frac{-D \theta_{i} N^{\prime \prime} n^{\prime}}{U_{q q}}>0$, 
with $U_{q q}<0$ from the second-order condition. In addition, we can see from (5) that as long as $\theta_{u}<1$, the desired quantity falls if choice is scrutinized. To see this, recall that the effect of the consumer's choice being observed is to make $\theta_{i}=\theta_{o}=1$, and it is immediate from (5) that $\frac{\partial q_{R, i}^{*}}{\partial \theta_{i}}<0$

The effect of a constraint on the actual amount consumed depends, among other things, on whether or not the consumer's choice is monitored. Observation of the consumer's consumption choice has two effects. The increase in $\theta_{i}$ discussed above and demonstrated in Figure 1 is fully captured in (5). In addition, a second effect exists - scrutiny of the consumer's action de facto forces her to consume no more than the limit, even if $q_{R, o}^{*}>R$. Thus, denoting the quantity consumed by $q_{R, i}^{c}$, if behavior is unobserved we have $q_{R, u}^{c}=q_{R, u}^{*}$, but if behavior is observed then $q_{R, u}^{c}=\min \left(R, q_{R, o}^{*}\right)$.

To demonstrate these effects, we begin with a case in which the new perceived norm exactly equals the quantity restriction $\left(n_{R}=R\right)$. In Figure 2 we show the effect of a restriction on consumption when it is unobserved. In the case depicted in the Figure the restriction was set above the desired quantity without a restriction. The effect of the restriction is to move the vertical portion of the cost curve to the right. As a result, the new desired quantity is $q_{R, u}^{*}>q_{\emptyset, u}^{*}$. In addition, in Figure $2 q_{R, u}^{*}>R$, but since the restriction is unobserved, $q_{R, u}^{c}=q_{R, u}^{*}$. Decreasing the restriction would not alter this result, but increasing the quantity limit sufficiently may yield a situation in which $q_{R, u}^{c}=q_{R, u}^{*}=R$, and with a large enough restriction, it can even lead to optimal consumption below the limit. 


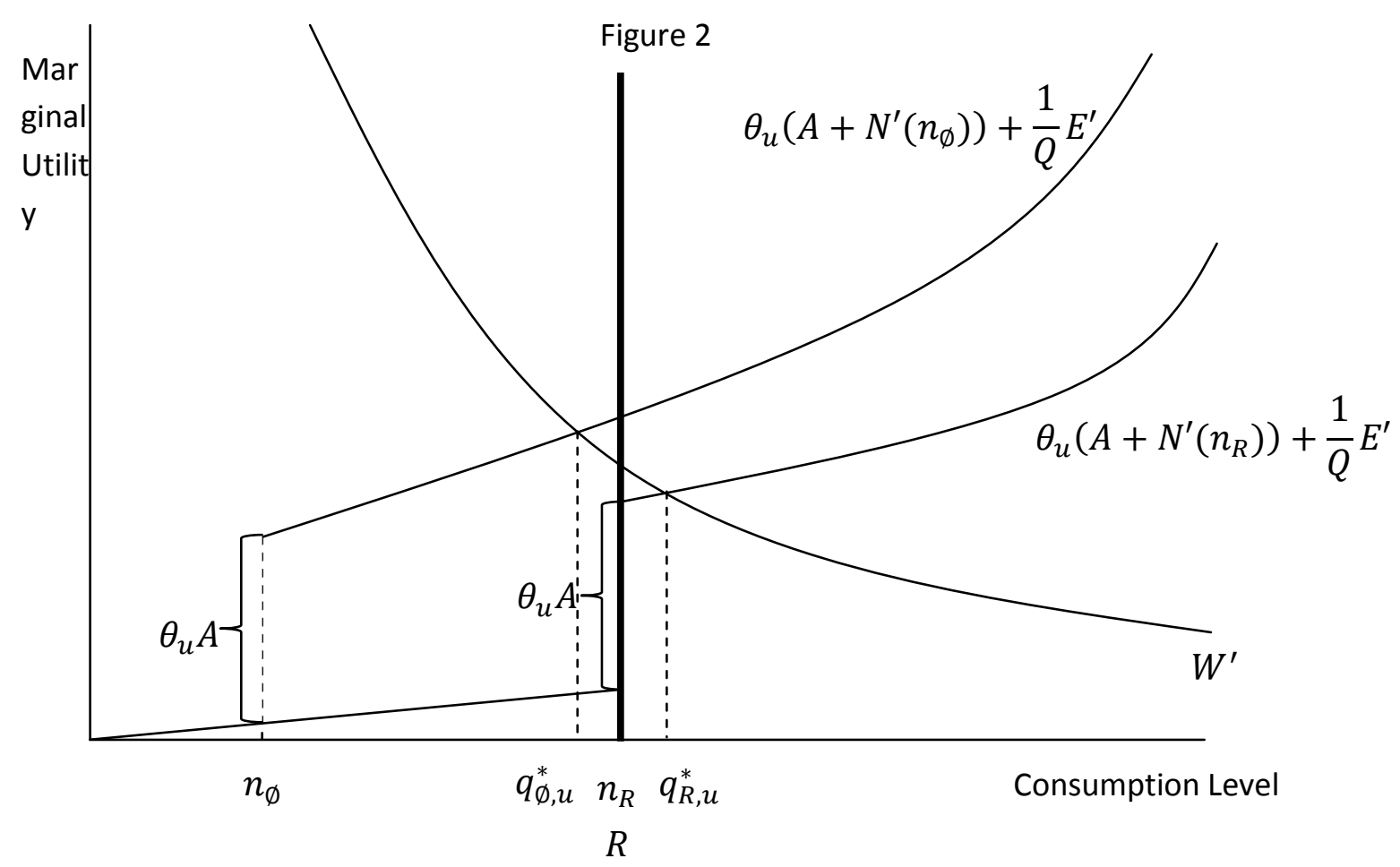

Figure 2, with a slight modification, can also be used to analyze the situation in which consumption is observed. The trivial changes required are simply to replace $\theta_{u}$ with $\theta_{o}=1$ in all places, i.e., to increase the vertical jump and the slope of both curves. These will lead to lower desired consumption than without observation, as in Figure 1. The more substantial change is to note that the constraint is binding when it is observed, so that in the case depicted $q_{R, u}^{c}=R<$ $q_{R, u}^{*}$

In Figure 3 we turn to a case in which $n_{R}<R$, and compare between the choice when observed and when unobserved when a restriction exists. We present an interesting instance in which consumption under observation is below the limit (but above the norm), but when she is unobserved she consumes more than the limit. Thus, the consumer always consumes her optimal quantity, but the fact that her choice is observed reduces her desired consumption level to below the limit. In other words, scrutiny does not only cause you to consume no more than the limit, it can cause you to consume strictly less than the limit. This, of course, does not cover all possibilities. 


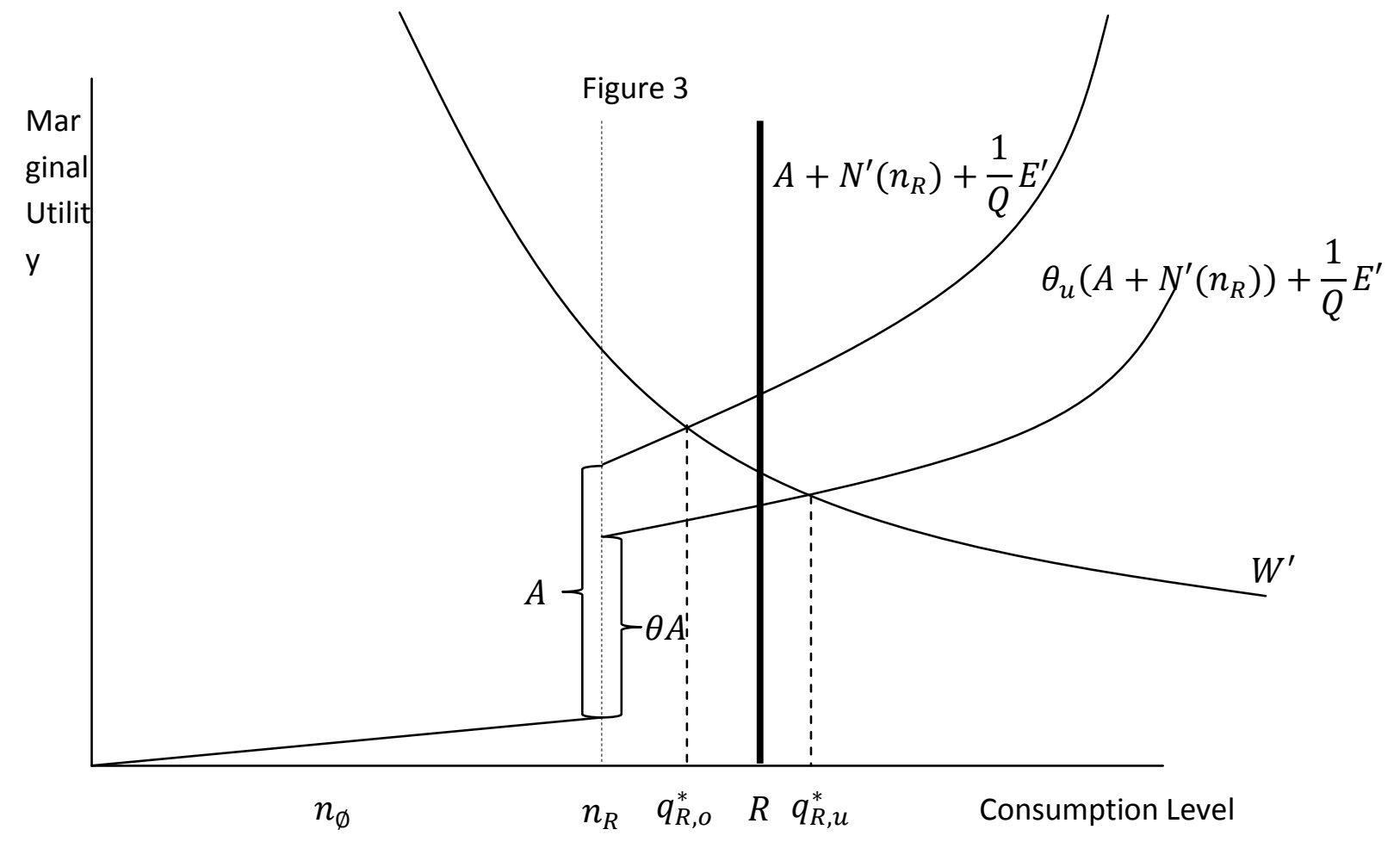

Note that the analysis of this figure is also appropriate for comparing two individuals who are identical aside from their value of $\theta_{u}$, with the higher curve representing the individual with a greater value of $\theta_{u}$. As is clear, a lower intrinsic concern for the cost to others (a lower value of $\left.\theta_{u}\right)$ leads to increased consumption.

Figure 4 presents a numerical example demonstrating how an increase in the quantity restriction, which also leads to an increase in the perceived norm, changes the quantity consumed. ${ }^{14}$ Since the restrictions are irrelevant for the unrestricted scenarios, the unrestricted quantities are independent of this change; rather, they are drawn for reference. As seen, consumption is greater when the consumer's actions are unobserved than when they are observed. This is true both with and without a restriction. A restriction can lead to lower consumption, but only when the choice is observed (as long as the restriction is greater than the unrestricted norm). Of course, a restriction can lead to an increase in consumption through the effect it has on the perceived norm. To summarize, a limit can only lead to increased

\footnotetext{
${ }^{14}$ The functions used for this simulation were $W=200 q-0.5 q^{2}, \theta_{u}=0.5, A=50, n_{\emptyset}=2, n=n_{\emptyset}+$ $0.5 D\left(R-n_{\emptyset}\right), N=(q-n)^{2}$ and $E=q^{2}$.
} 
consumption when the consumer's choice is unobserved, but when observed it can lead to decreased consumption if it is sufficiently low.

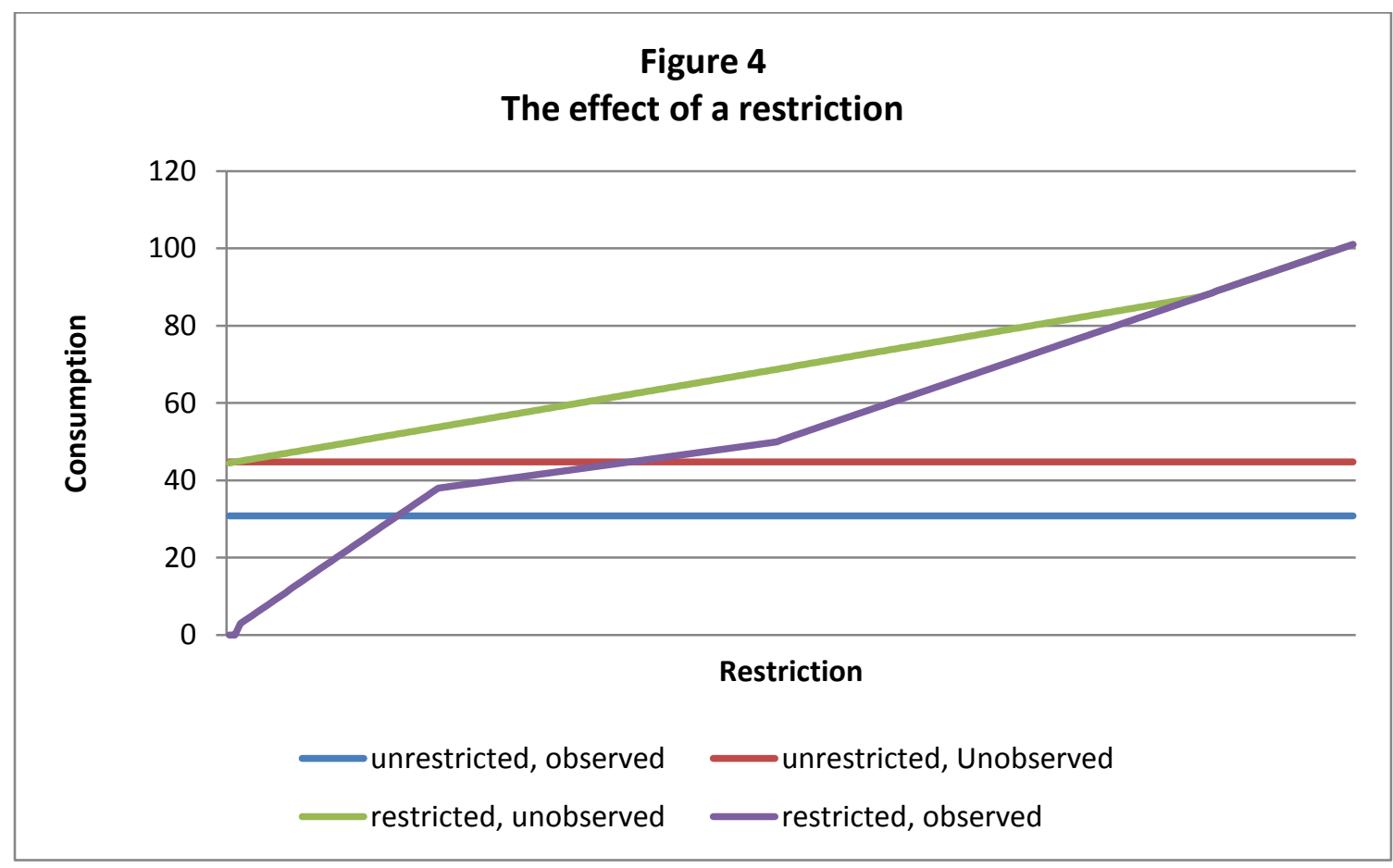

Finally, consider the effect of a change in the final term of (1). Returning to Figure 1, a decrease in the negative externality will result in lowering the $\frac{1}{Q} E^{\prime}$ curve, and, accordingly, all of the other curves. As a result, the quantity consumed will rise (unless consumption is observed and $\left.q_{R, o}^{*}>R\right)$.

\section{Experimental procedure and results}

Testing this theory requires a setup in which the focus of the experiment is peripheral from the subjects' perspectives, just as the availability of quasi-free goods is peripheral to the social interaction from which it stems. To this end, during the spring of 2013 and the fall of 2014, a stand was set up in different places on the campus of Bar-Ilan University, with a sign posted asking passersby to take a few minutes of their time to assist an MA student with his thesis project by answering a short questionnaire regarding their musical preferences. Prominently placed on the sign was a picture of a Kinder Schoko-Bon chocolate, and, sitting on 
the stand, was a clear plastic bowl filled with these chocolates. ${ }^{15}$ Under the picture, the sign promised "chocolate for participants." The questionnaire contained ten multiple choice questions and 1 short essay question, and required 2-5 minutes to complete. All told 652 subjects filled out questionnaires, and 1,247 chocolates were taken (and assumedly consumed). ${ }^{16}$

In our base setup, a bowl holding approximately 100 chocolates was placed on the stand, and subjects filled out the questionnaire and then took chocolates while being observed by the experimenter. The questionnaire started and ended by thanking the subjects for taking time to fill out the questionnaire, and inviting them to take chocolates from the bowl once the task was completed. The treatment concerned what was appended to that statement; while some questionnaires stated that the subjects were welcome to take "as many chocolates as they would like," others placed a limit on consumption. Thus, in the "quantity-restricted" sessions the subjects were instructed that they may take up to 2,3 or 5 chocolates. ${ }^{17}$ Table 1 contains the number of observations in each treatment. The results are presented in Figure 5 and are summarized in Table 1.

\footnotetext{
${ }^{15}$ The specific product was chosen for the following reasons: it is kosher, an important consideration in Israel; each unit is individually wrapped and sufficiently large $(3 \mathrm{~cm}$ length) to enable the experimenter to easily count the number of units taken; each unit is sufficiently heavy (6 grams) to allow the experimenter to discern the number of units taken in the blind sessions by using a sensitive scale; each unit is sufficiently small to make consumption of multiple units reasonable, yet sufficiently large to make consumption of dozens of units unreasonable.

${ }^{16}$ In all treatments there was a similar portion of consumers who chose not to take any chocolates. Excluding these consumers from the analysis does not affect any of the qualitative results or conclusions.

${ }^{17}$ Fifty seven of the no-constraint questionnaires (all in the base treatment) invited subjects to take chocolates (plural), but did not explicitly state that they could take "as many chocolates as they would like." Subjects who asked were told that they could take as many chocolates as they wished. Subject behavior was the same with and without the additional statement, and thus all the observations are included in the unrestricted sample. Excluding these observations does not impact any of the qualitative results in the paper.
} 
Figure 5. Consumption distribution, base conditions

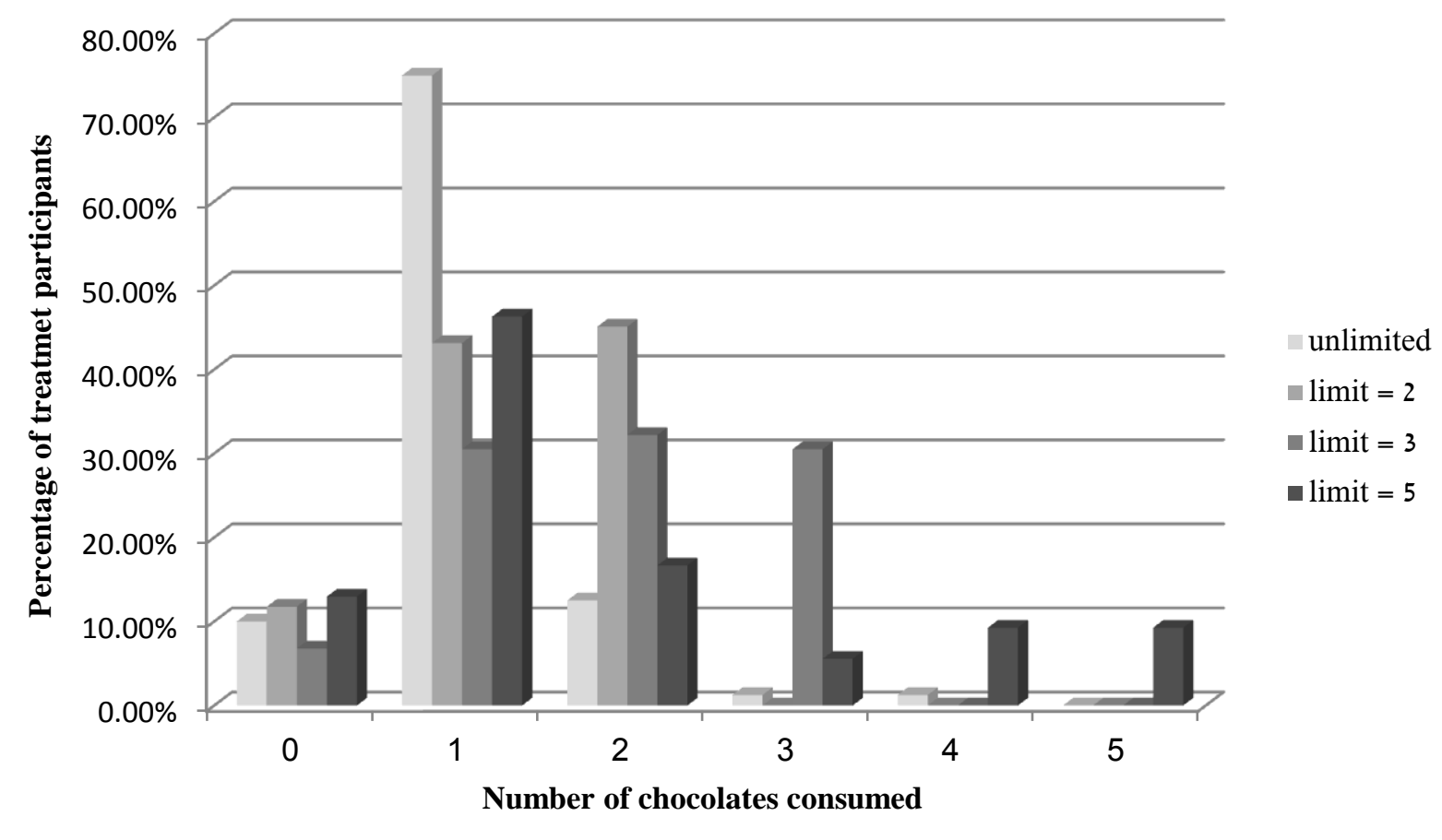

Table 1. Consumption, base conditions

\begin{tabular}{ccccc}
\hline Limit & Subjects & $\begin{array}{c}\text { Chocolates } \\
\text { consumed }\end{array}$ & $\begin{array}{c}\text { Average } \\
\text { consumption }\end{array}$ & Standard deviation \\
\hline none & 80 & 87 & 1.09 & 0.62 \\
2 & 51 & 68 & 1.33 & 0.68 \\
3 & 59 & 110 & 1.86 & 0.93 \\
5 & 54 & 97 & 1.8 & 1.48 \\
\hline
\end{tabular}

From Figure 5, the difference between the unrestricted consumption scenario and the restricted scenarios is evident: $75 \%$ of the unrestricted treatment subjects consumed exactly one chocolate, while less than $50 \%$ of the subjects whose consumption choices were restricted consumed one unit for all limits. In addition, only two out of eighty subjects (3\%) chose to consume more than 2 chocolates when consumption was unrestricted, while 18 of $59(31 \%)$ did so when there was a quantity restriction of 3, and 13 of 54 (24\%) when the restriction was 5.

Direct comparison of the averages in Table 1 does not properly test the hypothesis. Differences across treatments could stem from two sources - censoring, causing consumers to consume less than they would have desired, or changes in the underlying desired quantity caused 
by the presence of a constraint, as suggested by the model above. In order to test the theory, we must separate these two effects. Since we cannot determine how many chocolates were desired by those subjects located at the limit, we unravel the two effects by making pairwise comparisons between treatments, and artificially "censoring" consumption in the unrestricted (or less restricted) treatment, so that any observation which exceeds the relevant limit (the limit in the treatment for which we are conducting the comparison) will be treated as if the participant consumed precisely at the limit. We carry this out in Table 2, which present the results of pairwise comparisons between the unrestricted treatment and each of the restricted treatments.

Table 2. Scenario comparisons, basic conditions

\begin{tabular}{llllll}
\hline Limit & Average & Standard deviation & $\begin{array}{l}\text { Unrestricted censored } \\
\text { average }\end{array}$ & $\begin{array}{l}\text { Unrestricted } \\
\text { censored s.d. }\end{array}$ & t-value \\
\hline 2 & 1.33 & 0.68 & 1.05 & 0.5 & $2.55^{* *}$ \\
3 & 1.86 & 0.93 & 1.08 & 0.57 & $5.57^{* *}$ \\
5 & 1.8 & 1.48 & 1.09 & 0.62 & $3.38^{* *}$ \\
\hline
\end{tabular}

** statistically significant at $1 \%$ level

The first three columns in Table 2 are taken from Table 1. The fourth and fifth columns present the averages and standard deviations of the unrestricted treatment, after manually censoring the data to the relevant limit. That is, if the subject consumed, say, 4 chocolates in the unrestricted treatment, then, in the absence of the "norm" effect caused by the existence of a constraint, we assume that were she to be under a constraint to consume no more than 2 chocolates, she would have consumed at that limit. Thus, her consumption for sakes of comparison would be lowered to 2 chocolates. Similarly, if the constraint were 3 we assume she would have consumed 3 chocolates, but if the constraint were 5, we assume she would have consumed 4 chocolates, as she did in practice. This censoring allows us to compare the choices without a quantity restriction to those with a restriction, and any remaining difference is attributed to the "norm" effect presented in the theory.

As seen in Table 2, consumption is significantly higher with restrictions than without (1\% significance level), thus lending support to the theory. ${ }^{18} \mathrm{We}$ also compared the consumption in treatments with different restriction levels using a similar approach (i.e. censoring the higher limit scenario), and did not find any significant differences in consumption whenever a

\footnotetext{
${ }^{18}$ The number of observations is sufficient for use of t-tests (Central Limit Theorem). The same results are obtained when using a Mann-Whitney (Wilcoxon rank-sum) test.
} 
restriction existed. In other words, it is the existence of a restriction that affects behavior, and not just the level of the restriction that affects behavior in a more trivial manner.

In order to test for effects of the demographic variables, we also ran Tobit regressions. Initially, we included many demographic variables: a dummy for whether a restriction was present, sex (=1 if male), age, and fixed effects for whether religious (y/n), city size (small, medium, large), employment status (unemployed, part-time employment, fully employed), and field of study (exact sciences, social sciences, Jewish studies, and other). We do not report the coefficients for these latter dummy variables since, with a couple of exceptions, they were insignificant. ${ }^{19}$ Instead, we report the results of a more limited specification containing the dummy for a restriction, sex and age. None of the qualitative results are affected by the specification. Since each of the treatments with restrictions is censored at a different value, we ran three regressions, each time combining the observations with no quantity restrictions with those with a specific restriction. These are presented in Table 3.

Table 3

Tobit regressions, base case

\begin{tabular}{llcc|}
\hline Variable & Limit=2 & Limit=3 & Limit=5 \\
\hline Constant & $1.52^{* * *}$ & $1.53^{* * *}$ & $1.32^{* *}$ \\
& $(.225)$ & $(.251)$ & $(.346)$ \\
Restriction & $.455^{* * *}$ & $.927^{* * *}$ & $0.745^{* * *}$ \\
& $(.139)$ & $(.146)$ & $(.193)$ \\
Sex & .191 & .228 & -.049 \\
& $(.142)$ & $(.151)$ & $(.201)$ \\
Age & $-.020^{* *}$ & $-.022^{* *}$ & -.009 \\
& $(.009)$ & $(.010)$ & $(.013)$ \\
N & 131 & 139 & 134 \\
*** significant at the $1 \%$ level; ** significant at the 5\% level & & \\
Standard errors are in parentheses. &
\end{tabular}

\footnotetext{
${ }^{19}$ In the regression in which the limit was 3 , religious students were found to consume on average 0.34 more chocolates $(\mathrm{t}=2.29)$ than non-religious students and students in the social sciences consumed 0.39 fewer chocolates than those in faculties other than the three largest faculties $(\mathrm{t}=2.09)$.
} 
As seen, the presence of a quantity restriction significantly increases the quantity consumed. In addition, when the quantity was restricted to 2 or 3 chocolates older subjects consumed less than younger subjects. ${ }^{20}$ The sex of the subject did not affect consumption.

As discussed in the theory, a possible determinant of the consumption level of a quasifree good is its effect on others, as captured by the term $E\left(q_{i}, Z\right)$ in Equation 1 . In our case, the subject could be concerned with a negative externality on the experimenter who may run out of chocolates, or on other consumers who may face a shortage of chocolates. This was captured in the theory when we respecified the last term in Equation (1) as $E\left(\frac{q_{i}}{Q}\right)$, where $Q$ reflects the total number of chocolates in the bowl; as the portion of chocolates taken by the subject increases, the cost increases. To test this, we reran the experiment using a bowl with twice the capacity, and doubled the quantity of chocolates in the bowl. As discussed in the theory, this should have the effect of leading to increased consumption. Figure 6 presents the results, and the averages are presented in Table 4.

Figure 6. Consumption distribution, big-bowl condition

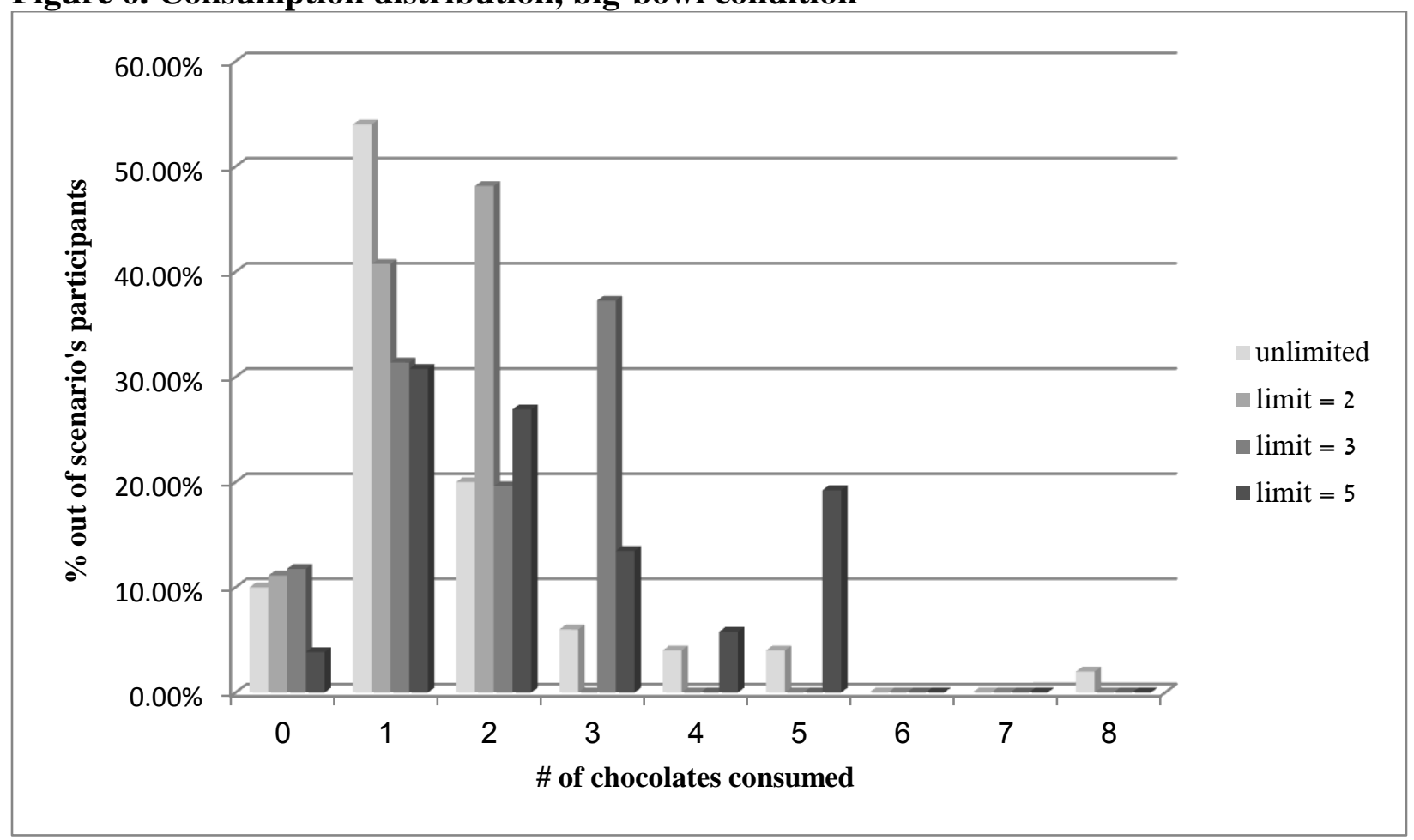

\footnotetext{
${ }^{20}$ The subjects' ages ranged from 19 to 65 , with the mean at 25 .
} 
Table 4. Consumption, big bowl condition.

\begin{tabular}{ccccc}
\hline Limit & Subjects & $\begin{array}{c}\text { Chocolates } \\
\text { consumed }\end{array}$ & $\begin{array}{c}\text { Average } \\
\text { consumption }\end{array}$ & Standard deviation \\
\hline none & 50 & 82 & 1.64 & 1.45 \\
2 & 54 & 74 & 1.37 & 0.67 \\
3 & 51 & 93 & 1.82 & 1.06 \\
5 & 52 & 127 & 2.44 & 1.54 \\
\hline
\end{tabular}

We begin by comparing across the different restriction treatments, as we did in the base case. Unlike in the base case, the average consumption is larger with no limit than with a limit of 2 , however this may be the effect of censoring since there are consumers who took $3,4,5$ and even 8 chocolates in the unrestricted treatment. We therefore proceed to manually restrict these consumers for the sake of comparison.

Table 5. Scenario comparisons, big-bowl condition

\begin{tabular}{llllll}
\hline Limit & Average & Standard deviation & $\begin{array}{l}\text { Unrestricted censored } \\
\text { average }\end{array}$ & $\begin{array}{l}\text { Unrestricted } \\
\text { censored s.d. }\end{array}$ & t-value \\
\hline 2 & 1.37 & 0.67 & 1.26 & 0.63 & 0.85 \\
3 & 1.82 & 1.06 & 1.42 & 0.87 & $2.1^{*}$ \\
5 & 2.44 & 1.54 & 1.58 & 1.23 & $3.07^{* *}$ \\
\hline ** statistically significant at 1\% level; * statistically significant at the 5\% level & &
\end{tabular}

Indeed, when we censor the average without a restriction is below that with a limit of 2 , however, the difference is not statistically significant. However, a significant difference remains for restrictions of 3 and 5 chocolates. Tobit regressions (not reported) yield the same results.

Comparing the results to those in the base case (Figure 5), we see a reduction from $75 \%$ to $54 \%$ in the portion of participants consuming a single chocolate when consumption is unrestricted, and more subjects consuming a relatively large number of chocolates (as many as 8). A t-test comparing behavior in the two settings shows that the increased average consumption level (from 1.09 to 1.64 ) is statistically significant at the $1 \%$ level ( $\mathrm{t}=2.541)$. Given the increase in average consumption in the unrestricted treatment, it is not surprising that a difference is no longer found between no restriction and a restriction of 2 chocolates.

Our final prediction is with respect to the effect of visibility on consumer choice. As presented in the model, consumption is expected to be higher when the person's choices are 
unobserved if there is a reputation component to social norm compliance. With this, if there is also a self-regarding component, consumption should still be higher with a restriction (greater than the norm) than without. To test this, we setup the stand in places where we could partition off an area, and the subjects in these treatments filled out the questionnaire and took their reward (the chocolates) while no one, including the experimenter, was able to observe them. ${ }^{21}$ Subjects were completely secluded, as no more than a single subject was allowed in the area at a time. Between subjects we used a sensitive scale to weigh the bowl, and were thus able to calculate the number of chocolates taken by each subject. The results are presented in Figure 7 and Table 6.

Figure 7. Consumption distribution, double-blind condition

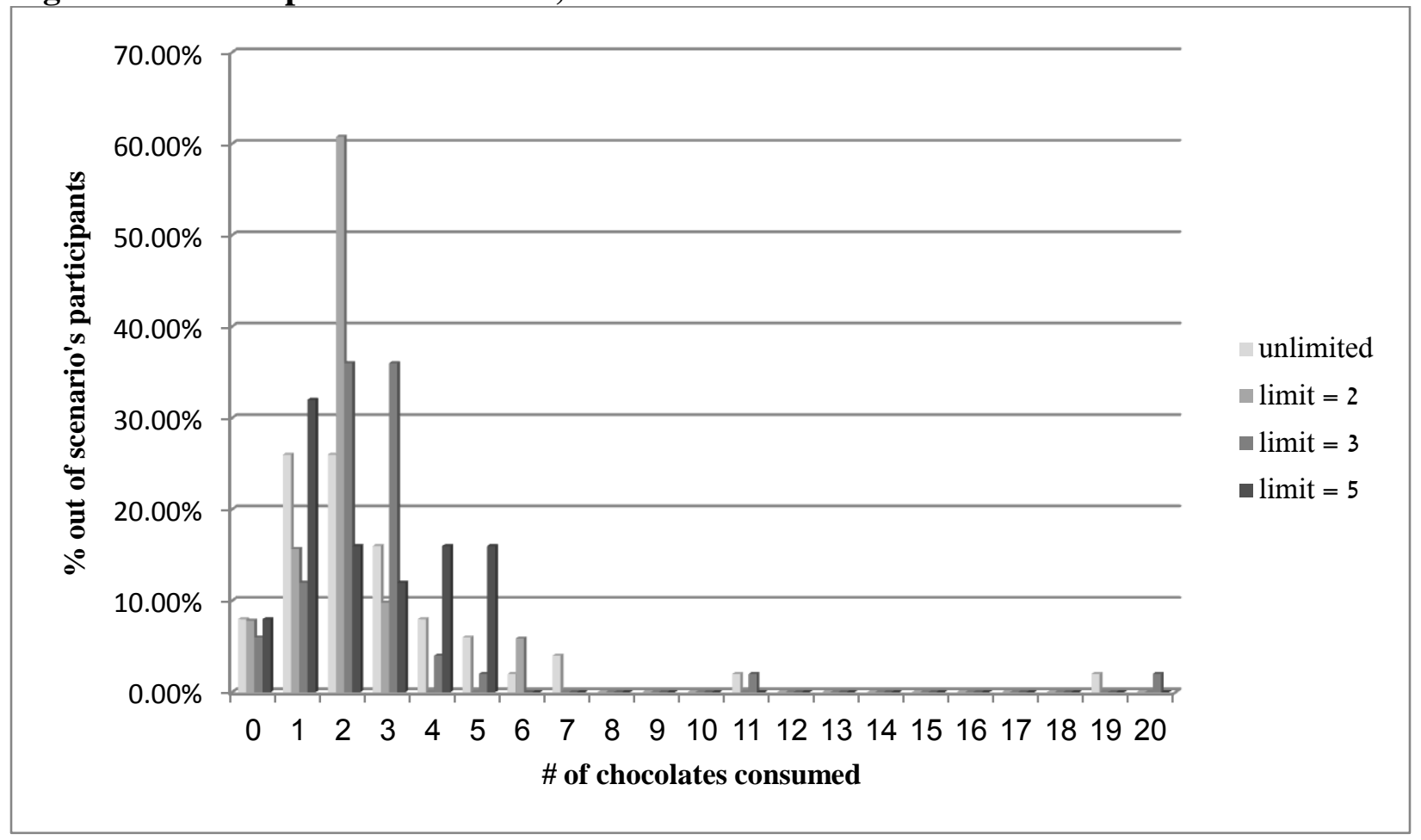

The first thing apparent from Figure 7 is that in this "double-blind" setup, some extreme consumption levels arise, with subjects taking as many as 20 chocolates (approximately $20 \%$ of the contents of the bowl)! More interestingly, this was true even when a quantity restriction was set; both the subject who took 20 chocolates and one of those who took 11 chocolates were instructed to take no more than 3 chocolates. In fact, $9 \%$ of the participants in the restricted

\footnotetext{
${ }^{21}$ Subjects were not told that their choices would be unobserved; they were simply sent into the partitioned area to complete the task.
} 
treatments exceeded the prescribed limit. In general, we see that outliers are much more common when choices are unobserved, likely because without social enforcement, the social norm effect weakens.

Table 6. Consumption, double-blind condition

\begin{tabular}{ccccc}
\hline Limit & Subjects & $\begin{array}{c}\text { Chocolates } \\
\text { consumed }\end{array}$ & $\begin{array}{c}\text { Average } \\
\text { consumption }\end{array}$ & Standard deviation \\
\hline None & 50 & 144 & 2.88 & 3.09 \\
2 & 51 & 103 & 2.02 & 1.23 \\
3 & 50 & 140 & 2.8 & 2.92 \\
5 & 50 & 122 & 2.44 & 1.63 \\
\hline
\end{tabular}

Again, we must censor the data in order to compare across treatments, but in this case we must censor the choices of those with restrictions also, and place those who exceeded their prescribed limit precisely at the limit. The reason this must be done is because many of the subjects may have felt bound by the restriction despite being unobserved. Note that, as a result, the means and standard deviation for the restricted treatments will also change when going from Table 6 to Table 7, where we present the comparison.

Table 7. Scenario comparisons, double-blind condition

\begin{tabular}{llllll}
\hline Limit & $\begin{array}{l}\text { Censored } \\
\text { average }\end{array}$ & $\begin{array}{l}\text { Censored standard } \\
\text { deviation }\end{array}$ & $\begin{array}{l}\text { Unrestricted censored } \\
\text { average }\end{array}$ & $\begin{array}{l}\text { Unrestricted } \\
\text { censored s.d. }\end{array}$ & t-value \\
\hline 2 & 1.69 & 0.61 & 1.58 & 0.64 & 0.89 \\
3 & 2.22 & 0.88 & 1.98 & 0.99 & 1.28 \\
5 & 2.44 & 1.63 & 2.38 & 1.53 & 0.19 \\
\hline
\end{tabular}

The results in the double blind treatment are starkly different from those above. While the average number of chocolates consumed is still lower when consumption is unrestricted, it is no longer significantly so. This also holds when we run Tobit regressions; no explanatory variable is significant, including the limitation dummy variable. These results seem to indicate that the value of $\theta_{u}$ is quite low, and perhaps even close to zero. If this is, indeed, the case, this would indicate that people tend to comply with the norm more because of how they will be viewed by others than because of self-esteem. 
Comparing choices in this treatment to those in the base treatment for each restriction level separately, we find that choices are significantly different in all cases (at the $1 \%$ significance level for the unrestricted treatment and a restriction of 2 , and at the $5 \%$ level for restrictions of 3 and 5). For instance, comparing Figures 3 and 1, only 26\% of the unrestricted subjects chose to take one chocolate in the double-blind treatment, while $75 \%$ did so in the base treatment. Interestingly, the percentage of subjects who chose not to take chocolates at all remained fairly stable throughout all 12 treatments.

Finally, for each restriction level separately, we compare the number of chocolates taken in each of the treatments. The regression results are presented in Table 8.

Table 8

Comparisons by restriction

\begin{tabular}{|c|c|c|c|c|c|c|c|}
\hline \multirow[t]{2}{*}{ Variable } & \multirow{2}{*}{$\begin{array}{c}\text { No } \\
\text { restriction }\end{array}$} & \multicolumn{2}{|c|}{ Limit $=2$} & \multicolumn{2}{|c|}{ Limit $=3$} & \multicolumn{2}{|c|}{ Limit $=5$} \\
\hline & & $\underline{\text { OLS }}$ & $\underline{\text { Tobit }}$ & $\underline{\mathrm{OLS}}$ & $\underline{\text { Tobit }}$ & $\underline{\mathrm{OLS}}$ & Tobit \\
\hline Constant & $\begin{array}{l}2.09^{* * * * *} \\
(0.54)\end{array}$ & $\begin{array}{l}1.94^{* * * *} \\
(0.30)\end{array}$ & $\begin{array}{l}2.74^{* * * *} \\
(0.47)\end{array}$ & $\begin{array}{l}1.73^{* * * *} \\
(0.48)\end{array}$ & $\begin{array}{l}2.15^{* * * *} \\
(0.40)\end{array}$ & $\begin{array}{c}2.05^{\text {**** }} \\
(0.53)\end{array}$ & $\begin{array}{l}2.14^{* * * *} \\
(0.60)\end{array}$ \\
\hline Big Bowl & $\begin{array}{c}0.54 \\
(0.33)\end{array}$ & $\begin{array}{l}-0.16 \\
(0.18)\end{array}$ & $\begin{array}{l}-0.01 \\
(0.27)\end{array}$ & $\begin{array}{l}-0.003 \\
(0.36)\end{array}$ & $\begin{array}{c}0.02 \\
(0.29)\end{array}$ & $\begin{array}{l}0.64^{* *} \\
(0.31)\end{array}$ & $\begin{array}{l}0.73^{\text {*** }} \\
(0.35)\end{array}$ \\
\hline Unobserved & $\begin{array}{l}1.78^{* * * *} \\
(0.33)\end{array}$ & $\begin{array}{c}0.67^{* * * *} \\
(0.18)\end{array}$ & $\begin{array}{l}0.89^{* * * *} \\
(0.30)\end{array}$ & $\begin{array}{c}0.87^{* * * *} \\
(0.36)\end{array}$ & $\begin{array}{l}0.56^{*} \\
(0.30)\end{array}$ & $\begin{array}{l}0.63^{\text {** }} \\
(0.31)\end{array}$ & $\begin{array}{l}0.70^{* *} \\
(0.35)\end{array}$ \\
\hline Sex & $\begin{array}{c}0.09 \\
(0.29)\end{array}$ & $\begin{array}{c}0.02 \\
(0.15)\end{array}$ & $\begin{array}{c}0.22 \\
(0.24)\end{array}$ & $\begin{array}{c}0.38 \\
(0.31)\end{array}$ & $\begin{array}{c}0.04 \\
(0.25)\end{array}$ & $\begin{array}{c}0.01 \\
(0.28)\end{array}$ & $\begin{array}{c}0.02 \\
(0.32)\end{array}$ \\
\hline Age & $\begin{array}{c}-0.042^{* *} \\
(0.02)\end{array}$ & $\begin{array}{c}-0.024^{* *} \\
(0.011)\end{array}$ & $\begin{array}{c}-0.041^{* *} \\
(0.017)\end{array}$ & $\begin{array}{c}-0.0003 \\
(0.016)\end{array}$ & $\begin{array}{c}-0.001 \\
(0.012)\end{array}$ & $\begin{array}{l}-0.01 \\
(0.02)\end{array}$ & $\begin{array}{l}-0.01 \\
(0.02)\end{array}$ \\
\hline $\mathrm{N}$ & 180 & 156 & 156 & 160 & 160 & 156 & 156 \\
\hline
\end{tabular}

We report the results for the restricted samples both using OLS and Tobit regressions. The use of the OLS regression is predicated on the fact that for all observations the limit was identical; therefore, the differences observed in behavior are the result of the change in the 
treatment. Thus, for instance, the coefficient on "Unobserved" measures the increase in consumption because the consumer's choice was not directly observed. This measurement, however, contains two effects: the increase in consumption because of the ability to consume more than permitted, and the increase because of an increase in the desire to consume under these differing conditions. The Tobit regression aims to unravel these effects, and the coefficients in these effects represent the change in the desire to consume, since the ability to consume more than the limit is purged.

In all cases, the quantity consumed increases with anonymity, as expected; however, it increases significantly more when consumption is unrestricted. This occurs because when there is no quantity restriction consumers tend to believe that the norm is low and therefore consume little, thus leaving a greater desire for increased consumption when unobserved. This can also be seen in our simulation in Figure 4. The size of the bowl only has a statistically significant effect when the restriction is large (although for the unrestricted observations it is significant at the $11 \%$ level). This has some appeal since a restriction of 5 is, for the most part, non-binding, so the decrease in the social effect (the concern with the welfare of the experimenter or other subjects) caused by a bigger bowl plays a more major part.

Finally, comparing the OLS and the Tobit regressions, we see that the effect of the double blind treatment is similar in both regressions, leading to the conclusion that it is not just the people at the limit who act differently when able to; it is a change in the desire to consume, as predicted in the model. The only sample in which the Tobit regression showed a lower coefficient that the OLS regression was when the restriction was set at 3 . This occurs because the two outliers with restrictions - consumption levels of 11 and 20 - occurred when the limit was 3.

\section{Conclusions}

In this paper we considered the effect of quantity restrictions and scrutiny on the consumption of quasi-free goods. A good is quasi-free if a consumer is allowed to consume the good for free, but the consumption choice is made in the context of a social setting (e.g., as an

employee, client, friend, etc.). Casual observation suggests that placing limitations on consumption can lead to an increase in the level of consumption of such goods, and that 
consumption is greater when consumption choices are made in private. We explained that when the price a consumer must pay for a good is zero and her consumption choice is made in the setting of a social group, the determining factors depend on how that person's choice will be perceived by others, and how she perceives that choice. We developed a model based on both reputation effects and self-image effects that help in explaining these observations. We then conducted a simple field experiment to test the theory. Interestingly, while we found the expected results, we also found that, of the two, the reputation effect is the dominant effect, and that when actions are not observed, consumption levels are no longer relatively low in the absence of a quantity restriction.

The implications for business practices would seem to be profound; by abolishing restrictions on, say, the number of vacation days or the number of sick days, companies would, it seems, be able to lower the number of such days used in practice, thereby saving substantial costs. Such a conclusion would be premature. Policies such as unlimited vacation days might be desirable for some categories of workers, however, it is doubtful that adopting such a policy for all workers is wise. Such a policy can be easily abused ${ }^{22}$, and even if this occurs in only a small number of cases, the effect on the firm and on the other workers could be profound. It is probably best to use such a policy only in instances in which the output of the worker can be easily defined and measured, and in which the workers are less likely to abuse their benefits, such as when social cohesion is strong. With respect to less pivotal free goods, such as soft drinks, the policy could be cost saving, and even if not, the additional cost is unlikely to be high. In either case, the gain from appearing to be more giving by not restricting consumption would very likely outweigh any negative monetary effect.

Finally, the static setup presented and tested in this paper may be more complicated when implemented in real life. In particular, dynamic considerations might play an important role in decision making. Thus, for instance, consumers or workers being offered unlimited quasi-free goods might fear that abuse of the policy could lead to strict restrictions being applied, or even complete negation of free access to the good. In such a case they may choose to voluntarily limit

\footnotetext{
${ }^{22}$ When employees at Los Angeles Department of Water and Power were allowed an unlimited number of sick days in 2012 , $10 \%$ of the 10,000 employees took at least twice the number of sick days previously allowed, and more than 200 employees took at least three times the original number, all thanks to the generous policy (http://articles.latimes.com/2013/jul/26/local/la-medwp-sick-20130726).
} 
consumption in order to avoid such a result. Of course, in a group setting this is a prisoners' dilemma, and each individual has a strong incentive to consume more, rather than less. In fact, if people recognize that increased consumption by others is likely to lead to a future limitation, they may choose to consume more in the short run in order to make up for the expected future deprivation. This, and other interesting dynamic considerations, is left to future research. 


\section{References}

Ariely, Dan, Uri Gneezy and Ernan Haruvy. 2008. "On the Discontinuity of Demand Curves Around Zero: Charging More and Selling More." In NA - Advances in Consumer Research Volume 35, eds. Angela Y. Lee and Dilip Soman, Duluth, MN : Association for Consumer Research, Pages: 36-38.

Burnham, Terence C. 2003. "Engineering Altruism: a Theoretical and Experimental Investigation of Anonymity and Gift Giving." Journal of Economic Behavior \& Organization, 50:133-144.

Deutsch, Morton and Harold B. Gerard. 1955. "A Study of Normative and Informational Social Influences upon Individual Judgement." Journal of Abnormal and Social Psychology, 51(3): 629-636.

Fehr, Ernst and Klaus M. Schmidt. 1999. "A Theory of Fairness, Competition, and Cooperation." Quarterly Journal of Economics, 114(3): 817-868.

Fiske, Alan P. 1992. "The Four Elementary Forms of Sociality: Framework for a Unified Theory of Social Relations." Psychological Review, 99(4): 689-723.

Funk, Patricia. 2005. "Theory and Evidence on the Role of Social Norms in Voting." (http://papers.ssrn.com/sol3/papers.cfm?abstract_id=627347).

Gneezy, Uri and Aldo Rustichini. 2000a. "Pay Enough or Don't Pay at All." Quarterly Journal of Economics, 115(3): 791-810.

Gneezy, Uri and Aldo Rustichini. 2000b. “A Fine Is a Price.” Journal of Legal Studies, 29(1): 117.

Hoffman, Elizabeth, Kevin McCabe, Keith Shachat and Vernon L. Smith. 1994. "Preferences, Property rights and Anonymity in Bargaining Games." Games and Economic Behavior, 7(3): 346-380.

Inman, J. Jeffery, Anil C. Peter and Priya Raghubir. 1997. "Framing the Deal: The Role of Restrictions in Accentuating Deal Value." Journal of Consumer Research, 24(4): 68-79.

Kahneman, Daniel and Amos Tversky. 1974. "Judgement under Uncertainty: Heuristics and Biases." Science, 185: 1124-1131.

Kandori, Michihiro. 1992. "Social Norms and Community Enforcement." Review of Economic Studies, 59(1): 63-80.

Levitt, Steven D. and John A. List. 2007. "What Do Laboratory Experiments Measuring Social Preferences Reveal About the Real World?” Journal of Economic Perspectives, 21(2): 153-174.

Lynn, Michael. 1991. "Scarcity Effects on Value: A Quantitative Review of the Commodity Theory Literature." Psychology and Marketing, 8(1): 43-57. 
Lynn, Michael. 1992. "Scarcity's Enhancement of Desirability: The Role of Naive Economic Theories." Basic and Applied Social Psychology, 13(1): 67-78.

Nicolau, Juan L. and Ricardo Sellers. 2012. "The Free Breakfast Effect: An Experimental Approach to the Zero Price Model in Tourism." Journal of Travel Research, 51(3): 243-249.

Nogami, Tatsuya and Jiro Takai. 2008. "Effects of Anonymity on Antisocial Behavior Committed by Individuals." Psychological Reports, 102: 119-130.

Ressler, Cali and Jody Thompson. 2008. Why Work Sucks and How to Fix it. New York, NY: Penguin Group.

Shampan'er, Kristina and Dan Ariely. 2006. "How Small is Zero Price? The True Value of Free Products." Working Paper, Federal Reserve Bank of Boston.Slovic, Paul, Melissa L. Finucane, Ellen Peters and Donald G. MacGregor. 2002. "Rational actors or rational fools: Implications of the affect heuristic for behavioral economics." Journal of Socio-Economics, 31(4): 329-342.

Soetevent, Adrian R. 2005. "Anonymity in Giving in a Natural Context - A Field Experiment in Thirty Churches.” Journal of Public Economics, 89(11-12): 2301-2323.

Van Exel, Job, Werner Brouwer, Bernard van den Berg and Marc Koopmanschap. 2006. "With a Little Help from an Anchor: Discussion and Evidence of Anchoring Effects in Contingent Valuations." Journal of Socio-Economics, 35(5): 836-853.

Verhallen, Theo M. M. and Henry S. J. Robben. 1994. "Scarcity and Preference: An Experiment on Unavailability and Product Evaluation." Journal of Economic Psychology, 15(2): 315-331.

Wansink, Brian, Robert J. Kent and Stephen J. Hoch. 1998. "An Anchoring and Adjustment Model of Purchase Quantity Decisions.” Journal of Marketing Research, 35(1): 71-81. 